\begin{tabular}{|c|c|}
\hline Citation & $\begin{array}{l}\text { Sonneville R, Vanhorebeek I, (2014), } \\
\text { Critical illness-induced dysglycemia and the brain. } \\
\text { Intensive Care Med. } 2015 \text { Feb;41(2):192-202 }\end{array}$ \\
\hline Archived version & $\begin{array}{l}\text { Author manuscript: the content is identical to the content of the published } \\
\text { paper, but without the final typesetting by the publisher }\end{array}$ \\
\hline Published version & http://dx.doi.org/10.1007/s00134-014-3577-0 \\
\hline Journal homepage & http://link.springer.com \\
\hline Author contact & $\begin{array}{l}\text { your email greet.vandenberghe@med.kuleuven.be } \\
\text { your phone number + } 32(0) 16344021\end{array}$ \\
\hline IR & https://lirias.kuleuven.be/handle/123456789/472282 \\
\hline
\end{tabular}

(article begins on next page) 


\section{Critical illness-induced dysglycemia and the brain}

Romain Sonneville (MD, $\mathrm{PhD})^{1,2}$, Ilse Vanhorebeek $(\mathrm{PhD})^{1}$, Heleen M. den Hertog $(\mathrm{MD}, \mathrm{PhD})^{1,3}$, Fabrice Chrétien (MD, PhD) ${ }^{4}$, Djillali Annane (MD, $\left.\mathrm{PhD}\right)^{5}$, Tarek Sharshar (MD, $\left.\mathrm{PhD}\right)^{5}$, Greet Van den Berghe (MD, $\mathrm{PhD})^{1}$

${ }^{1}$ Clinical Department and Laboratory of Intensive Care Medicine, Division of Cellular and Molecular Medicine, KU Leuven, Belgium; ${ }^{2}$ Service de Réanimation Médicale et Infectieuse and INSERM U1148, Hôpital Bichat-Claude-Bernard, Assistance Publique Hôpitaux de Paris AP-HP, Université Paris Diderot, Sorbonne Paris Cité, Paris, France; ${ }^{3}$ Department of Neurology, Erasmus University Medical Center, Rotterdam, The Netherlands; ${ }^{4}$ Department of Human Histopathology and Experimental Models, Institut Pasteur, Paris, France; ${ }^{5}$ Department of Intensive Care Medicine and EA4342, Raymond Poincaré University Hospital, Assistance Publique Hôpitaux de Paris AP-HP, Université Versailles Saint-Quentin, Garches, France

\section{Corresponding author:}

Prof. Greet Van den Berghe, Clinical Department and Laboratory of Intensive Care Medicine, Cellular and Molecular Medicine, KU Leuven, Herestraat 49, B 3000, Leuven, Belgium.

Email: greet.vandenberghe@med.kuleuven.be, Tel: +32 16 344021, Fax: +32 16344015

Word count: Abstract: 250 words; Text: 3730 words; Tables and figures: Tables: 2; Figures: 1

Keywords: hyperglycemia, neuron, astrocyte, insulin

Take home message: Persistent hyperglycemia is associated with significant neuronal and glial changes during critical illness. Preventing hyperglycemia with insulin infusion during critical illness holds promise as a neuroprotective strategy to prevent acute brain dysfunction as well as long-term cognitive impairment in survivors of critical illness. When occurring, hypoglycemia should be corrected promptly, avoiding overcorrection with excessive glucose reperfusion.

A 140-character tweet: Preventing hyperglycemia in ICU holds promise to protect against acute brain dysfunction and long-term cognitive impairment. 


\begin{abstract}
Purpose: Dysglycemia is a characteristic feature of critical illness associated with adverse outcome. Whether dysglycemia contributes to brain dysfunction during critical illness and long-term neurological complications is unclear. We give an overview of glucose metabolism in brain and review the literature on critical illness-induced dysglycemia and brain.
\end{abstract}

Methods: Medline database search using relevant search terms on dysglycemia, critical illness, acute brain injury/dysfunction, and randomized controlled trial.

Results: Hyperglycemia has been associated with deleterious effects on the nervous system. Underlying mechanisms in critical illness remain largely speculative and are often extrapolated from knowledge in diabetes-mellitus. Increased hyperglycemia-induced blood-brain-barrier permeability, oxidative stress and microglia activation may play a role and compromise neuronal and glial cell integrity. Hypoglycemia is feared as critically ill patients cannot recognize or communicate hypoglycemic symptoms, which furthermore are masked by sedation and analgesia. However, observational data on impact of brief hypoglycemia on the brain in critical illness are controversial. Secondary analysis of two large randomized studies suggested neuroprotection by strict glycemic control with insulin during intensive care, with lowered intracranial pressure, reduction of seizures, and better long-term rehabilitation in patients with isolated brain injury, and reduced incidence of critical illness-polyneuromyopathy in the general critically ill patient population. Several subsequent studies failed to reproduce neurological benefit, likely explained by methodological issues, among which divergent achieved glucose levels and inaccurate glucose monitoring tools.

Conclusions: Preventing hyperglycemia during critical illness holds promise as neuroprotective strategy to preserve brain cell viability and prevent acute brain dysfunction and long-term cognitive impairment in survivors. 


\section{INTRODUCTION}

Dysglycemia, in the form of hyperglycemia, hypoglycemia and/or marked glucose variability, is a characteristic feature of critical illness, whether patients have previously diagnosed diabetes or not [1]. Various mechanisms contribute, including pre-existing abnormal glucose metabolism, systemic and immune responses, and use of medications such as steroids and parenteral nutrition [1]. Both hyperglycemia and hypoglycemia have been associated with significant morbidity and mortality of these patients [2]. By inducing injury to vulnerable areas of the nervous system, critical illnessinduced dysglycemia may contribute to the development of neurologic complications of critical illness, including delirium and polyneuropathy in ICU and long-term cognitive impairment in ICU survivors [3, 4]. Interestingly, onset of delirium is characterized by an acute brain dysfunction involving the hippocampus and frontal cortex, two areas that are extremely vulnerable to metabolic insults, such as hypoxia, ischemia, hypoglycemia and possibly hyperglycemia [5, 6]. However, whether a causal relation exists between dysglycemia and brain dysfunction or injury in critically ill patients remains unclear. This review provides an overview of brain glucose metabolism and of the data on the effects of dysglycemia and blood glucose control with insulin on the brain during critical illness.

A medline database search was conducted using relevant search terms on dysglycemia (hyperglycemia, hypoglycemia, glucose variability, insulin) and brain dysfunction or injury (delirium, cognitive dysfunction, acute brain injury). For the effects of blood glucose control with insulin on the nervous system we focused on evidence from randomized controlled studies conducted in critically ill patients with or without acute brain injury. 


\section{BRAIN GLUCOSE METABOLISM}

Glucose is the most important substrate for brain. Under normal conditions, brain glucose concentration approximates $25-30 \%$ of the circulating levels and thus is highly dependent on plasma concentrations [7]. The normal cerebral glucose demand is approximately $5 \mathrm{mg} / 100 \mathrm{~g}$ of brain tissue/min, but with a higher demand of $5-15 \mathrm{mg} / 100 \mathrm{~g}$ of brain tissue/min in areas with greater metabolic activities, i.e. cortex basal ganglia and hippocampus.

\section{Glucose transport}

Before brain cells can take up glucose to support their metabolism, glucose must cross the blood-brain barrier (BBB). The concentration gradients for glucose and other nutrients are from blood to brain and thus regulated by brain metabolic utilization and plasma concentration [7]. Glucose is transported across the BBB via the 55kDa-isoform of glucose transporter (GLUT) 1, which is exclusively expressed in endothelial cells from the BBB (Table 1) [8]. The density of GLUT1 at the abluminal membrane is higher than at the luminal membrane [8]. This asymmetrical distribution provides a homeostatic control of glucose entry into the brain, by preventing accumulation in brain interstitial fluid at levels higher than in blood. The adult brain adapts to hypoxia by increasing GLUT1 at the BBB, mediated by hypoxia-inducible-factor-1. Another isoform of GLUT-1, that of $45 \mathrm{kDa}$, is mainly localized in astrocytes and epithelial cells. GLUT1 mRNA is acutely induced in hypothalamus and cortex during insulin-induced hypoglycemia [9]. This is likely explained by hypoglycemia, and not by hyperinsulinemia, since fasting is characterized by low insulin and low glucose levels and also induces GLUT1 mRNA. Whether reverse transport adaptation takes place during hyperglycemia is less clear. A study in healthy humans suggested no major modification in maximal transport velocity or affinity to the BBB glucose transporter during acute hyperglycemia [10]. Down-regulation of GLUT1 has been reported in cells cultured under hyperglycemia [11]. In contrast, Pelligrino et al. found an increased BBB glucose transport in chronic hyperglycemia [12]. Further studies are needed to clarify whether the human brain possesses additional adaptive mechanisms that modulate BBB glucose transport in case of hyperglycemia or hypoglycemia. 
The human brain also expresses several other GLUTs (Table 1), including GLUT3 for neuronal glucose uptake [8]. Recent studies suggest a role for GLUT2 in monitoring changes in brain glucose levels, based on its expression in specialized glucose-sensing cells in the paraventricular nucleus of the hypothalamus, arcuate nucleus and lateral hypothalamic region. GLUT5 is involved in transport of glucose and mainly fructose, in brain exclusively in microglia [13]. The insulin-sensitive GLUT4 and GLUT8 might contribute to CNS effects of insulin. GLUT4 expression is limited to neuronal bodies and dendrites and often colocalises with insulin receptors. Cellular GLUT4 localization in brain may be sensitive to changes in insulin levels as described for muscle and adipose tissue. GLUT8 is present in neurons and GLUT8 knockout $\left(\right.$ Slc2a8 $\left.{ }^{-/}\right)$mice showed behavioural alterations, presumably due to deficient glucose metabolism [14].

Apart from glucose transporters, several monocarboxylate transporters are found in the brain (Table 1). Astrocytes mainly express the lactate transporters MCT1 and MCT4, while neurons mainly express MCT1 and MCT2 [8].

Widely varying substrate affinities (with the lower the $\mathrm{K}_{\mathrm{m}}$ the higher the affinity) have been reported for the GLUTs and MCTs (Table 1), with a higher apparent substrate affinity for the neuronal transporters (GLUT3, MCT2) than for those in astrocytes (GLUT1, MCT1, MCT4) [8, 15]. It thus seems likely that any potential neurotoxicity of persistent hyperglycemia is driven indirectly rather than directly as, according to $\mathrm{K}_{\mathrm{m}}$ values, neuronal transporters appear to be saturated under physiologic conditions with normal fasting blood glucose levels of 4.4-6.1 mmol/l. In contrast, glucose transport to astrocyes and/or microglial cells may increase significantly under high glucose levels, inducing deleterious changes, including excessive glycolyis and accumulation of lactic acid in brain tissue, release of proinflammatory cytokines by glial cells, and subsequent neuronal damage. Caution is warranted, however, as the reported affinities depend on in vitro cell culture conditions, including $\mathrm{pH}$, substrate analogue used, cell type and purity in which the transporters are expressed, and coexpression of other transporters and enzymes that phosphorylate glucose $[8,15]$.

Interestingly, insulin is not required for glucose entry into the brain or metabolism by neurons or glial cells [16]. Nevertheless, the brain is rich in insulin receptors with substantial regional variation, and especially abundant in the olfactory bulb, hippocampus, hypothalamus and amygdala. 


\section{Brain energetics and glucose metabolism}

Glucose represents the brain's only substrate under normal physiologic conditions. Under basal conditions, $90 \%$ of glucose uptake in neurons is aerobically used for production of energy to maintain ionic homeostasis. The brain contains less than $1 \mathrm{mmol} / \mathrm{kg}$ of free glucose reserve. Astrocytes, but not neurons, are able to store glycogen. This capacity gives astrocytes a key role in the regulation of brain metabolic responses to activity, as they can rapidly convert glycogen to pyruvate/lactate to be further metabolized in the tricarboxylic acid cycle or used for glutamate biosynthesis [17]. The release of lactate can support neuronal function for a limited period [17]. During sustained neuronal activation, reflected by glutamatergic activity, glutamate-induced glycolysis in astrocytes provides lactate as preferential oxidative substrate to neurons, a concept known as "astrocyte-neuron lactate shuttle" (Figure 1). In addition to glucose, lactate is then taken up by activated neurons via specific MCTs and oxidized to contribute to their energy needs. Actually, recent in vivo rat studies added evidence that lactate represents a relevant neuronal energy source [18]. First, lactate largely maintained neuronal activity and integrity in the absence of glucose, as loss of a voltage-sensitive dye signal found during severe insulin-induced hypoglycemia was completely prevented by lactate infusion, suggesting direct neuroprotection. Second, the brain preferred lactate as energy substrate over glucose when both substrates were available. Third, lactate appeared readily metabolized by non-injured brain in an activity-dependent manner. Other studies suggested that neuronal lactate import is essential for longterm memory formation and maintenance of long-term potentiation of synaptic strength [19]. Neuroprotection by exogenous lactate has been documented in various conditions (prolonged starvation, diabetes, ischemia), but beneficial effects of lactate on the acutely injured human brain are scarce. Preliminary clinical data suggest that hypertonic lactate solutions may improve cerebral energy metabolism and may be effective to treat elevated intracranial pressure after traumatic brain injury [20], though larger studies are needed.

Ketone bodies, such as $\beta$-hydroxybutyrate and acetoacetate, are other energy sources for brain metabolism during states as fasting or ketoacidosis. Under starvation conditions, ketone utilization can contribute up to $30 \%$ of the brain's fuel for oxidative metabolism. 


\section{DYSGLYCEMIA AND THE BRAIN IN CRITICAL ILLNESS}

Clinical complications of dysglycemia develop much faster as in patients with diabetes. We summarize the responses triggered in brain by impaired glucose homeostasis and their impact on the brain in diabetes and critical illness.

\section{Hyperglycemia}

Patients with type 1 diabetes who have been exposed to chronic hyperglycemia show marked structural brain abnormalities, including hippocampal injury, changes in white matter microstructure and cerebral atrophy, contributing to neurocognitive impairment [21]. Elderly patients with diabetes have accelerated progression of brain atrophy with significant consequences on cognition [22]. Experimental data in streptozotocin-induced diabetes suggest that diabetes impairs astrocyte viability and function. This is illustrated by decreased glial acidic fibrillary protein (GFAP) levels in cerebral cortex, hippocampus and cerebellum at 8 weeks, together with attenuated GFAP immunoreactivity at 4 weeks in hippocampus and white matter [23]. Furthermore, hyperglycemia and diabetes impair gapjunctional communication in various cell types and notably astrocytes. Insulin treatment prevented these diabetes-induced astrocyte alterations.

Association studies on stress hyperglycemia and brain damage are mostly performed in the setting of traumatic brain injury or cerebral ischemia. Hyperglycemia is frequently observed in patients with acute brain injury and is associated with an increased risk of death and of poor functional recovery in survivors [24]. In cerebral ischemia, hyperglycemia has various deleterious effects, including increased infarct volume, impaired recanalization and decreased reperfusion, increased damage caused by reperfusion injury and direct tissue injury [25]. After ischemia and reperfusion injury, experimental data suggest that hyperglycemia not only affects neurons, but also contributes to astrocyte death by increased DNA oxidation [26]. An association between hyperglycemia and microglial apoptosis was suggested in patients who had died from septic shock [27]. In patients surviving the acute respiratory distress syndrome hyperglycemia predicted adverse cognitive sequellae [28]. Hyperglycemia may 
theoretically contribute to brain injury in critical illness by different mechanisms. An up-regulation of neuronal and astrocytic glucose transporters through regulators that are increased in critical illness and acute brain injury could lead to exaggerated passive transport of glucose into the brain. BBB disruption in systemic inflammation and sepsis have also been suggested [29]. The consequent neuronal glucose overload may induce exaggerated oxidative stress, via overactivation of NADPH oxidase, with generation or deficient scavenging of reactive oxygen species (ROS) [30]. In a neuropathological study in non-survivors of critical illness, hyperglycemia was shown to aggravate critical illness-induced neuropathological changes [31]. Patients with uncontrolled hyperglycemia (14.1 $\pm 4.6 \mathrm{mmol} / \mathrm{l})$ showed increased microglial activation, an important reduction in astrocyte density and activation status, more than 9-fold increased neuronal and glial apoptosis and a 1.5-2-fold increase in damaged neurons in hippocampus and frontal cortex. Most abnormalities were attenuated with moderate hyperglycemia $(9.6 \pm 1.8 \mathrm{mmol} / \mathrm{l})$ and virtually absent with normoglycemia $(5.8 \pm 0.5 \mathrm{mmol} / \mathrm{l})$. Similar findings were observed after 7 days in frontal cortex of hyperglycemic $(17.5 \pm 1.8 \mathrm{mmol} / \mathrm{l})$ versus normoglycemic $(4.7 \pm 0.7 \mathrm{mmol} / \mathrm{l})$ critically ill rabbits. After 3 days of critical illness, only microglial changes were observed under hyperglycemia $(18.6 \pm 0.9 \mathrm{mmol} / \mathrm{l})$. These findings suggest that pro-inflammatory effects of hyperglycemia could induce over-activation of microglia, leading to exaggerated and prolonged local production of inflammatory mediators in the brain. This would affect neuronal functioning and viability, leading to astroglial cell apoptosis, microglial activation and subsequent neuronal damage and apoptosis [31]. Interestingly, hyperglycemia has also been associated with apoptosis of microglial cells in non-survivors of critical illness [27].

Increased oxidative stress and inflammatory responses may also play a role in reperfusion injury and mitochondrial dysfunction and anaerobic glycolysis in direct tissue injury in the brain [25].

\section{Hypoglycemia}

Transient hypoglycemia deprives the brain of its major fuel and may result in functional brain failure [32]. Normally, fasting circulating glucose levels in adults range from 4.4 to $6.1 \mathrm{mmol} / \mathrm{l}$. Initially, declining plasma glucose levels activate defences against hypoglycemia. First, insulin secretion 
decreases when blood glucose levels drop below the lower limit of normal. Below $3.8 \mathrm{mmol} / \mathrm{l}$, increments in pancreatic $\beta$-cells' glucagon and adrenomedullary epinephrine secretion occur. If the aforementioned mechanisms fail to abort the hypoglycemic episode, lower glucose levels (below 3.5 $\mathrm{mmol} / \mathrm{l}$ ) induce autonomic symptoms, including anxiety, tachycardia, sweating and mydriasis. These symptoms usually prompt the behavioral defence and food ingestion. If glycemia falls below 2.8-3.0 $\mathrm{mmol} / \mathrm{l}$, neuroglycopenic symptoms, such as delirium or seizures can be seen. Stupor and coma may occur at glucose levels below 2.3-2.7 mmol/l [33]. As the blood glucose levels drop to the range of 1-2 $\mathrm{mmol} / \mathrm{l}$, theta waves increase and delta waves appear on electroencephalogram. In rats, hypoglycemia did not induce neuronal death unless the electroencephalogram became isoelectric, whatever the blood glucose level [34]. Hypoglycemic brain injury differs from ischemia in its neuropathologic distribution. In hypoglycemia, necrosis of the hippocampal dentate gyrus can occur and a predilection for the superficial layers 2 and 3 of the cortex is sometimes seen [6]. Cerebellum and brainstem are universally spared. As described by Sakel in 1937, insulin-induced coma was performed in humans for a period of 30 minutes to treat schizophrenia and drug addiction [35]. A 60-minute duration led to tragic results, as "reversible coma” was transformed into "irreversible coma" and the patient would no longer wake up with glucose administration [6]. More recent experimental data suggest that 10-20 minutes of isoelectric hypoglycemia induces significant neuronal damage in subiculum, hippocampus, and caudate nucleus [36]. Repeated MRI images in diabetes patients in a persistent vegetative state after at least 8 hours of hypoglycemia revealed specific lesions in the bilateral basal ganglia, cerebral cortex, substantia nigra and hippocampus, which suggests the particular vulnerability of these areas to hypoglycemia [37]. Interestingly, neuronal damage may be triggered during glucose reperfusion after hypoglycemia, rather than by the hypoglycemic episode itself [30].

Several mechanisms are thought to be involved in hypoglycemia-induced neuronal death. During hypoglycemia, glycolytic flux is decreased, thus lowering tissue levels of lactate and pyruvate. The resulting shortage of acetyl-CoA, with which oxaloacetate condenses, induces a transamination (oxaloacetate + glutamate $=>$ aspartate $+\alpha$-ketoglutarate) that leads to an increase in brain tissue aspartate and decrease in glutamate, while both are increased in the extracellular space. The 
extracellular aspartate released during hypoglycemia damages neurons by an excitotoxic mechanism. During hypoglycemia, gamma-amino-butyric acid (GABA) is released in the extracellular space [38]. However, its inhibitory effects are insufficient and the balance shifts toward excitation, which is why seizures can be seen. In addition, profound tissue alkalosis develops, due to increased ammonia production as the cell catabolizes proteins and deaminates amino acid and to shortage of lactate [6]. Other mechanisms include a series of events in which nitric oxide production triggers vesicular zinc release, in turn activating NADPH oxidase and ROS production, as well as poly-ADP-ribose polymerase (PARP-1) and mitochondrial permeability transition [36]. Suh et al. provided evidence that hypoglycemic superoxide production and neuronal death were increased by NADPH oxidase activation during glucose reperfusion rather than by hypoglycemia itself [30]. Several mechanisms involved in hypoglycemia-induced neuronal injury $\left(\mathrm{Zn}^{2+}\right.$ release, ROS production, microglia activation) appeared inhibited by hypothermia and aggravated by hyperthermia during glucose reperfusion [39].

Hypoglycemia in critically ill patients is a feared complication. Patients may be unable to recognize or communicate hypoglycemic symptoms, because of altered mental status, intubation or the severe illness itself. Furthermore, clinical symptoms of the autonomic response to hypoglycemia (sweating, tachycardia, tremor) and central nervous symptoms (dizziness, blurred vision, confusion, altered mental status, and eventually seizures) may be masked by concomitant diseases or treatments (sedation, analgesia, mechanical ventilation). In two large clinical studies, a brief episode of severe hypoglycemia $<2.2 \mathrm{mmol} / \mathrm{l}$ did not cause early deaths, coincided with only minor immediate and transient morbidity in a minority of patients, and did not lead to late neurological sequellae among hospital survivors [40]. Nevertheless, apart from hyperglycemia also hypoglycemia has been associated with an increased risk of ICU or in-hospital death in a dose-response, even when mild, with greater risk the lower the glucose levels fall [41-43]. Hypoglycemia has been associated with lower performance in one domain of a full range of cognitive functions (visuospatial skills) at least one year after critical illness in adult patients, but hyperglycemia and glycemic fluctuations were as well and hence could not be excluded as confounders [44]. No matching for baseline risk factors had been 
performed. Interestingly, patients with a higher severity of illness have a higher risk of developing a hypoglycemic episode [2, 41]. Data on the potential impact of hypoglycemia on the brain in critical illness are scarce. Microdialysis studies in acute brain injury patients suggested that even normoglycemia may be detrimental by dangerously lowering brain glucose levels, contributing to metabolic crisis based on an increased lactate/pyruvate ratio [45], though cause and consequence could not be differentiated. Interestingly, a patient who experienced extreme hypoglycemia for several hours in ICU made an uneventful recovery, with no apparent neurological dysfunction at discharge, no neurological or cognitive symptoms at six months follow-up, and normal clinical examination, EEG and brain CT scan one year later [46]. However, irreversible brain injury and fatal outcome have been reported for another patient with prolonged extreme hypoglycemia [47].

Translating to clinical practice, it is clear that blood glucose levels should be carefully monitored to quickly detect and correct hypoglycemic episodes, to minimise any risk of irreversible brain injury. Overcorrection should be avoided as excessive glucose reperfusion may worsen neurological injury.

\section{Glucose variability}

Blood glucose variability, reflected by the standard deviation of blood glucose levels in ICU, have been associated with patient outcomes, including short-term mortality in general critically ill patients $[2,48,49]$, and neurologic outcomes in patients with acute brain injury [50, 51]. Reduced mortality with intensive insulin therapy in the Leuven studies could not be attributed to an effect on blood glucose amplitude variation [2]. Nevertheless, reducing amplitude variation and entropy of the blood glucose signal, irrespective of blood glucose concentration, may produce clinical benefits, including neuroprotection, by reducing glucose reperfusion injury. So far, randomized clinical trials targeting blood glucose variability in patients with acute brain injury are lacking. 


\section{IS BLOOD GLUCOSE CONTROL WITH INSULIN DURING CRITICAL ILLNESS NEUROPROTECTIVE?}

Randomized controlled studies in critically ill patients showed that blood glucose control with intensive insulin therapy (IIT) may reduce morbidity and mortality [52-54]. These studies also suggested that IIT beneficially affects the central and peripheral nervous system of the patients [55, 56]. Clinical neuroprotective effects included reduction of intracranial pressure, reduction of seizures, and better long-term rehabilitation in patients with isolated brain injury, together with a lower incidence of critical illness-induced neuromyopathy. Subsequent randomized controlled studies in critically ill patients with acute brain injury [57-63] or with acute ischemic stroke [64-66] showed mostly no benefit on neurological outcomes (Table 2). A recent systematic review on acute ischaemic stroke concluded that intravenous insulin administration aiming to maintain serum glucose within a specific range did not improve the neurological deficit [67]. Interestingly, however, two meta-analyses conducted in neurocritical care patients suggested better neurological outcome with insulin therapy, despite an increased risk of hypoglycemia, especially when glucose levels in the conventional glycemic control group were permitted to be relatively high and glucose limits tightened in the strict glycemic control group, and especially when study quality improved [68, 69]. Important methodological differences in glucose regulation and quality might account for the discrepancies between the individual studies [70]. These include different target ranges for blood glucose and achieved glucose levels in control and intervention groups (Table 2). Other aspects are differences in routes for insulin administration, types of infusion-pumps, sampling sites, and accuracies of glucose monitoring tools [70]. A center participating in NICE-SUGAR [71] showed inaccurate, mostly substantially higher glucose levels with the Lifescan point-of-care instrument than with the blood gas analyzer. This difference could be even higher than the difference achieved among the study arms and likely increased the chance for undetected hypoglycemia. Also different nutritional strategies and varying levels of expertise may have contributed to the different outcomes [70]. A post-hoc study of NICE-SUGAR like other studies showed an association of both iatrogenic and spontaneous hypoglycemia with an increased risk of death, though could not prove any causal relationship [72]. 
Nevertheless, it is thought that the potential benefit of IIT may thus be negated by an increased incidence of severe hypoglycemia [52, 53, 71], which might be per se deleterious for the CNS, either directly [6], or indirectly during glucose reperfusion [30]. However, neuropathological alterations in post-mortem brain biopsies of hippocampus and frontal cortex appeared comparable for patients who experienced a brief episode of severe hypoglycemia and those who did not, findings that were confirmed in vivo in critically ill animals [31]. A recent randomized controlled study in critically ill children also found a reduced morbidity and mortality with IIT [54]. In this study, IIT did not evoke neurological damage detectable by circulating levels of S100B (marker of astrocyte damage) or neuron-specific enolase (NSE, marker of neuronal damage) despite an increased incidence of hypoglycemia [73]. Interestingly, patients who experienced an episode of hypoglycemia in ICU had higher S100B and NSE levels, but already from admission onwards and thus before the hypoglycemic event. Furthermore, a nested case-control study showed that both markers decreased after hypoglycemia unlike in the corresponding controls evaluated on the matched days [73]. This may reflect an increased incidence of hypoglycemia in the most severely ill patients, rather than elevated neurological damage markers being caused by hypoglycemia. More importantly, four years after ICU admission, children who had been treated with tight glucose control during their stay in ICU did not score worse on any measure of intelligence than those who had received the conventional glucose management, and actually showed better motor coordination and cognitive flexibility [74]. A brief episode of hypoglycemia evoked by tight glucose control did not negatively affect neurocognitive outcome, as shown in a propensity score-matched subgroup of children with and without hypoglycemia. Also, in patients with type 1 diabetes, no evidence of substantial long-term declines in cognitive function with IIT was found in a large group of patients who were followed up for an average of 18 years [75]. 


\section{CONCLUSIONS AND PERSPECTIVES}

Severe disturbances in glucose homeostasis may contribute to brain dysfunction and injury during critical illness. Prolonged hyperglycemia is associated with significant brain alterations in patients with or without acute brain injury. Maintaining normoglycemia with insulin infusion during critical illness holds promise to preserve brain cell viability and to prevent acute brain dysfunction as well as long-term cognitive impairment in survivors of critical illness, but requires further thorough investigation in well-designed, well-performed adequately powered randomized clinical studies. The impact of brief hypoglycemia on the brain in critical illness remains controversial. Hypoglycemia should be corrected promptly, avoiding overcorrection with excessive glucose reperfusion. 


\section{REFERENCES}

1. Van den Berghe G (2004) How does blood glucose control with insulin save lives in intensive care? J Clin Invest 114:1187-1195

2. Meyfroidt G, Keenan DM, Wang X, Wouters PJ, Veldhuis JD, Van den Berghe G (2010) Dynamic characteristics of blood glucose time series during the course of critical illness: effects of intensive insulin therapy and relative association with mortality. Crit Care Med 38:1021-1029

3. Ely EW, Shintani A, Truman B, Speroff T, Gordon SM, Harrell FE, Jr., Inouye SK, Bernard GR, Dittus RS (2004) Delirium as a predictor of mortality in mechanically ventilated patients in the intensive care unit. JAMA 291:1753-1762

4. Girard TD, Jackson JC, Pandharipande PP, Pun BT, Thompson JL, Shintani AK, Gordon SM, Canonico AE, Dittus RS, Bernard GR, Ely EW (2010) Delirium as a predictor of long-term cognitive impairment in survivors of critical illness. Crit Care Med 38:1513-1520

5. Sharshar T, Gray F, Lorin de la Grandmaison G, Hopkinson NS, Ross E, Dorandeu A, Orlikowski D, Raphael JC, Gajdos P, Annane D (2003) Apoptosis of neurons in cardiovascular autonomic centres triggered by inducible nitric oxide synthase after death from septic shock. Lancet 362:1799-1805

6. Auer RN (2004) Hypoglycemic brain damage. Metab Brain Dis 19:169-175

7. Choi IY, Lee SP, Kim SG, Gruetter R (2001) In vivo measurements of brain glucose transport using the reversible Michaelis-Menten model and simultaneous measurements of cerebral blood flow changes during hypoglycemia. J Cereb Blood Flow Metab 21:653-663 
8. Simpson IA, Carruthers A, Vannucci SJ (2007) Supply and demand in cerebral energy metabolism: the role of nutrient transporters. J Cereb Blood Flow Metab 27:17661791

9. Mastaitis JW, Wurmbach E, Cheng H, Sealfon SC, Mobbs CV (2005) Acute induction of gene expression in brain and liver by insulin-induced hypoglycemia. Diabetes 54:952-958

10. Hasselbalch SG, Knudsen GM, Capaldo B, Postiglione A, Paulson OB (2001) Bloodbrain barrier transport and brain metabolism of glucose during acute hyperglycemia in humans. J Clin Endocrinol Metab 86:1986-1990

11. Klip A, Tsakiridis T, Marette A, Ortiz PA (1994) Regulation of expression of glucose transporters by glucose: a review of studies in vivo and in cell cultures. FASEB J 8:43-53

12. Pelligrino DA, LaManna JC, Duckrow RB, Bryan RM, Jr., Harik SI (1992) Hyperglycemia and blood-brain barrier glucose transport. J Cereb Blood Flow Metab 12:887-899

13. Payne J, Maher F, Simpson I, Mattice L, Davies P (1997) Glucose transporter Glut 5 expression in microglial cells. Glia 21:327-331

14. Schmidt S, Gawlik V, Holter SM, Augustin R, Scheepers A, Behrens M, Wurst W, Gailus-Durner V, Fuchs H, Hrabe de Angelis M, Kluge R, Joost HG, Schurmann A (2008) Deletion of glucose transporter GLUT8 in mice increases locomotor activity. Behav Genet 38:396-406

15. Barros LF, Bittner CX, Loaiza A, Porras OH (2007) A quantitative overview of glucose dynamics in the gliovascular unit. Glia 55:1222-1237 
16. Seaquist ER, Damberg GS, Tkac I, Gruetter R (2001) The effect of insulin on in vivo cerebral glucose concentrations and rates of glucose transport/metabolism in humans. Diabetes 50:2203-2209

17. Benarroch EE (2010) Glycogen metabolism: metabolic coupling between astrocytes and neurons. Neurology 74:919-923

18. Wyss MT, Jolivet R, Buck A, Magistretti PJ, Weber B (2011) In vivo evidence for lactate as a neuronal energy source. J Neurosci 31:7477-7485

19. Suzuki A, Stern SA, Bozdagi O, Huntley GW, Walker RH, Magistretti PJ, Alberini CM (2011) Astrocyte-neuron lactate transport is required for long-term memory formation. Cell 144:810-823

20. Bouzat P, Sala N, Suys T, Zerlauth JB, Marques-Vidal P, Feihl F, Bloch J, Messerer M, Levivier M, Meuli R, Magistretti PJ, Oddo M (2014) Cerebral metabolic effects of exogenous lactate supplementation on the injured human brain. Intensive Care Med $40: 412-421$

21. Kodl CT, Franc DT, Rao JP, Anderson FS, Thomas W, Mueller BA, Lim KOSeaquist ER (2008) Diffusion tensor imaging identifies deficits in white matter microstructure in subjects with type 1 diabetes that correlate with reduced neurocognitive function. Diabetes 57:3083-3089

22. van Elderen SG, de Roos A, de Craen AJ, Westendorp RG, Blauw GJ, Jukema JW, Bollen EL, Middelkoop HA, van Buchem MA, van der Grond J (2010) Progression of brain atrophy and cognitive decline in diabetes mellitus: a 3-year follow-up. Neurology 75:997-1002

23. Coleman ES, Dennis JC, Braden TD, Judd RL, Posner P (2010) Insulin treatment prevents diabetes-induced alterations in astrocyte glutamate uptake and GFAP content in rats at 4 and 8 weeks of diabetes duration. Brain Res 1306:131-141 
24. Ntaios G, Egli M, Faouzi M, Michel P (2010) J-shaped association between serum glucose and functional outcome in acute ischemic stroke. Stroke 41:2366-2370

25. Kruyt ND, Biessels GJ, Devries JH, Roos YB (2010) Hyperglycemia in acute ischemic stroke: pathophysiology and clinical management. Nat Rev Neurol 6:145155

26. Muranyi M, Ding C, He Q, Lin Y, Li PA (2006) Streptozotocin-induced diabetes causes astrocyte death after ischemia and reperfusion injury. Diabetes 55:349-355

27. Polito A, Brouland JP, Porcher R, Sonneville R, Siami S, Stevens RD, Guidoux C, Maxime V, de la Grandmaison GL, Chretien FC, Gray F, Annane D, Sharshar T (2011) Hyperglycaemia and apoptosis of microglial cells in human septic shock. Crit Care 15:R131

28. Hopkins RO, Suchyta MR, Snow GL, Jephson A, Weaver LK, Orme JF (2010) Blood glucose dysregulation and cognitive outcome in ARDS survivors. Brain Inj 24:14781484

29. Alexander JJ, Jacob A, Cunningham P, Hensley L, Quigg RJ (2008) TNF is a key mediator of septic encephalopathy acting through its receptor, TNF receptor-1. Neurochem Int 52:447-456

30. Suh SW, Gum ET, Hamby AM, Chan PH, Swanson RA (2007) Hypoglycemic neuronal death is triggered by glucose reperfusion and activation of neuronal NADPH oxidase. J Clin Invest 117:910-918

31. Sonneville R, den Hertog HM, Guiza F, Gunst J, Derese I, Wouters PJ, Brouland JP, Polito A, Gray F, Chretien F, Charlier P, Annane D, Sharshar T, Van den Berghe G, Vanhorebeek I (2012) Impact of hyperglycemia on neuropathological alterations during critical illness. J Clin Endocrinol Metab 97:2113-2123 
32. Cryer PE (2007) Hypoglycemia, functional brain failure, and brain death. J Clin Invest $117: 868-870$

33. Ben-Ami H, Nagachandran P, Mendelson A, Edoute Y (1999) Drug-induced hypoglycemic coma in 102 diabetic patients. Arch Intern Med 159:281-284

34. Auer RN, Olsson Y, Siesjo BK (1984) Hypoglycemic brain injury in the rat. Correlation of density of brain damage with the EEG isoelectric time: a quantitative study. Diabetes 33:1090-1098

35. Sakel M (1937) The methodical use of hypoglycemia in the treatment of psychoses. Am J Psychiatry 151:240-247

36. Suh SW, Hamby AM, Swanson RA (2007) Hypoglycemia, brain energetics, and hypoglycemic neuronal death. Glia 55:1280-1286

37. Fujioka M, Okuchi K, Hiramatsu KI, Sakaki T, Sakaguchi S, Ishii Y (1997) Specific changes in human brain after hypoglycemic injury. Stroke 28:584-587

38. Sandberg M, Butcher SP, Hagberg H (1986) Extracellular overflow of neuroactive amino acids during severe insulin-induced hypoglycemia: in vivo dialysis of the rat hippocampus. J Neurochem 47:178-184

39. Shin BS, Won SJ, Yoo BH, Kauppinen TM, Suh SW (2010) Prevention of hypoglycemia-induced neuronal death by hypothermia. J Cereb Blood Flow Metab $30: 390-402$

40. Van den Berghe G, Wilmer A, Milants I, Wouters PJ, Bouckaert B, Bruyninckx F, Bouillon R, Schetz M (2006) Intensive insulin therapy in mixed medical/surgical intensive care units: benefit versus harm. Diabetes 55:3151-3159

41. Krinsley JS, Grover A (2007) Severe hypoglycemia in critically ill patients: risk factors and outcomes. Crit Care Med 35:2262-2267 
42. Egi M, Bellomo R, Stachowski E, French CJ, Hart GK, Taori G, Hegarty C, Bailey M (2010) Hypoglycemia and outcome in critically ill patients. Mayo Clinic proceedings 85:217-224

43. Krinsley JS, Schultz MJ, Spronk PE, Harmsen RE, van Braam Houckgeest F, van der Sluijs JP, Melot C, Preiser JC (2011) Mild hypoglycemia is independently associated with increased mortality in the critically ill. Crit Care 15:R173

44. Duning $\mathrm{T}$, van den Heuvel I, Dickmann A, Volkert T, Wempe C, Reinholz J, Lohmann H, Freise H, Ellger B (2010) Hypoglycemia aggravates critical illnessinduced neurocognitive dysfunction. Diabetes Care 33:639-644

45. Oddo M, Schmidt JM, Carrera E, Badjatia N, Connolly ES, Presciutti M, Ostapkovich ND, Levine JM, Le Roux P, Mayer SA (2008) Impact of tight glycemic control on cerebral glucose metabolism after severe brain injury: a microdialysis study. Crit Care Med 36:3233-3238

46. Piot VM, Verrijcken A, Vanhoof M, Mertens I, Soetens F (2012) Full neurological recovery after extreme hypoglycemia during intensive insulin therapy: a case report. J Diabetes Sci Technol 6:973-977

47. Sinha S, Jayaram R, Hargreaves CG (2007) Fatal neuroglycopaenia after accidental use of a glucose $5 \%$ solution in a peripheral arterial cannula flush system. Anaesthesia 62:615-620

48. Egi M, Bellomo R, Stachowski E, French CJ, Hart G (2006) Variability of blood glucose concentration and short-term mortality in critically ill patients. Anesthesiology $105: 244-252$

49. Ali NA, O'Brien JM, Jr., Dungan K, Phillips G, Marsh CB, Lemeshow S, Connors AF, Jr.Preiser JC (2008) Glucose variability and mortality in patients with sepsis. Crit Care Med 36:2316-2321 
50. Jacka MJ, Torok-Both CJ, Bagshaw SM (2009) Blood glucose control among critically ill patients with brain injury. Can J Neurol Sci 36:436-442

51. Kurtz P, Claassen J, Helbok R, Schmidt J, Fernandez L, Presciutti M, Stuart RM, Connolly ES, Lee K, Badjatia NMayer SA (2014) Systemic glucose variability predicts cerebral metabolic distress and mortality after subarachnoid hemorrhage: a retrospective observational study. Crit Care 18:R89

52. Van den Berghe G, Wouters P, Weekers F, Verwaest C, Bruyninckx F, Schetz M, Vlasselaers D, Ferdinande P, Lauwers PBouillon R (2001) Intensive insulin therapy in the critically ill patients. N Engl J Med 345:1359-1367

53. Van den Berghe G, Wilmer A, Hermans G, Meersseman W, Wouters PJ, Milants I, Van Wijngaerden E, Bobbaers HBouillon R (2006) Intensive insulin therapy in the medical ICU. N Engl J Med 354:449-461

54. Vlasselaers D, Milants I, Desmet L, Wouters PJ, Vanhorebeek I, van den Heuvel I, Mesotten D, Casaer MP, Meyfroidt G, Ingels C, Muller J, Van Cromphaut S, Schetz M, Van den Berghe G (2009) Intensive insulin therapy for patients in paediatric intensive care: a prospective, randomised controlled study. Lancet 373:547-556

55. Van den Berghe G, Schoonheydt K, Becx P, Bruyninckx F, Wouters PJ (2005) Insulin therapy protects the central and peripheral nervous system of intensive care patients. Neurology 64:1348-1353

56. Hermans G, Wilmer A, Meersseman W, Milants I, Wouters PJ, Bobbaers H, Bruyninckx F, Van den Berghe G (2007) Impact of intensive insulin therapy on neuromuscular complications and ventilator dependency in the medical intensive care unit. Am J Respir Crit Care Med 175:480-489 
57. Azevedo JR, Lima ER, Cossetti RJ, Azevedo RP (2007) Intensive insulin therapy versus conventional glycemic control in patients with acute neurological injury: a prospective controlled trial. Arquivos de neuro-psiquiatria 65:733-738

58. Bilotta F, Spinelli A, Giovannini F, Doronzio A, Delfini R, Rosa G (2007) The effect of intensive insulin therapy on infection rate, vasospasm, neurologic outcome, and mortality in neurointensive care unit after intracranial aneurysm clipping in patients with acute subarachnoid hemorrhage: a randomized prospective pilot trial. Journal of neurosurgical anesthesiology 19:156-160

59. Bilotta F, Caramia R, Cernak I, Paoloni FP, Doronzio A, Cuzzone V, Santoro A, Rosa G (2008) Intensive insulin therapy after severe traumatic brain injury: a randomized clinical trial. Neurocrit Care 9:159-166

60. Bilotta F, Caramia R, Paoloni FP, Delfini R, Rosa G (2009) Safety and efficacy of intensive insulin therapy in critical neurosurgical patients. Anesthesiology 110:611619

61. Yang M, Guo Q, Zhang X, Sun S, Wang Y, Zhao L, Hu E, Li C (2009) Intensive insulin therapy on infection rate, days in NICU, in-hospital mortality and neurological outcome in severe traumatic brain injury patients: a randomized controlled trial. International journal of nursing studies 46:753-758

62. Green DM, O'Phelan KH, Bassin SL, Chang CW, Stern TS, Asai SM (2010) Intensive versus conventional insulin therapy in critically ill neurologic patients. Neurocrit Care 13:299-306

63. Coester A, Neumann CR, Schmidt MI (2010) Intensive insulin therapy in severe traumatic brain injury: a randomized trial. J Trauma 68:904-911

64. Gray CS, Hildreth AJ, Sandercock PA, O'Connell JE, Johnston DE, Cartlidge NE, Bamford JM, James OF, Alberti KG (2007) Glucose-potassium-insulin infusions in 
the management of post-stroke hyperglycaemia: the UK Glucose Insulin in Stroke Trial (GIST-UK). Lancet Neurol 6:397-406

65. Johnston KC, Hall CE, Kissela BM, Bleck TP, Conaway MR, GRASP Investigators (2009) Glucose Regulation in Acute Stroke Patients (GRASP) trial: a randomized pilot trial. Stroke 40:3804-3809

66. Rosso C, Corvol JC, Pires C, Crozier S, Attal Y, Jacqueminet S, Deltour S, Multlu G, Leger A, Meresse I, Payan C, Dormont D, Samson Y (2012) Intensive versus subcutaneous insulin in patients with hyperacute stroke: results from the randomized INSULINFARCT trial. Stroke 43:2343-2349

67. Bellolio MF, Gilmore RM, Ganti L (2014) Insulin for glycaemic control in acute ischaemic stroke. The Cochrane database of systematic reviews 1:CD005346

68. Ooi YC, Dagi TF, Maltenfort M, Rincon F, Vibbert M, Jabbour P, Gonzalez LF, Rosenwasser R, Jallo J (2012) Tight glycemic control reduces infection and improves neurological outcome in critically ill neurosurgical and neurological patients. Neurosurgery 71:692-702

69. Kramer AH, Roberts DJ, Zygun DA (2012) Optimal glycemic control in neurocritical care patients: a systematic review and meta-analysis. Crit Care 16:R203

70. Van den Berghe G, Schetz M, Vlasselaers D, Hermans G, Wilmer A, Bouillon R, Mesotten D (2009) Intensive insulin therapy in critically ill patients: NICE-SUGAR or Leuven blood glucose target? J Clin Endocrinol Metab 94:3163-70

71. NICE-SUGAR Study Investigators, Finfer S, Chittock DR, Su SY, Blair D, Foster D, Dhingra V, Bellomo R, Cook D, Dodek P, Henderson WR, Hebert PC, Heritier S, Heyland DK, McArthur C, McDonald E, Mitchell I, Myburgh JA, Norton R, Potter J, Robinson BG, Ronco JJ (2009) Intensive versus conventional glucose control in critically ill patients. N Engl J Med 360:1283-1297 
72. NICE-SUGAR Study Investigators, Finfer S, Liu B, Chittock DR, Norton R, Myburgh JA, McArthur C, Mitchell I, Foster D, Dhingra V, Henderson WR, Ronco JJ, Bellomo R, Cook D, McDonald E, Dodek P, Hebert PC, Heyland DK, Robinson BG (2012) Hypoglycemia and risk of death in critically ill patients. N Engl J Med 367:1108-1118

73. Vanhorebeek I, Gielen M, Boussemaere M, Wouters PJ, Grandas FG, Mesotten D, Van den Berghe G (2010) Glucose dysregulation and neurological injury biomarkers in critically ill children. J Clin Endocrinol Metab 95:4669-4679

74. Mesotten D, Gielen M, Sterken C, Claessens K, Hermans G, Vlasselaers D, Lemiere J, Lagae L, Gewillig M, Eyskens B, Vanhorebeek I, Wouters PJ, Van den Berghe G (2012) Neurocognitive development of children 4 years after critical illness and treatment with tight glucose control: a randomized controlled trial. JAMA 308:16411650

75. Jacobson AM, Musen G, Ryan CM, Silvers N, Cleary P, Waberski B, Burwood A, Weinger K, Bayless M, Dahms W, Harth J (2007) Long-term effect of diabetes and its treatment on cognitive function. N Engl J Med 356:1842-1852 


\section{FUNDING}

Supported by the Foundation for Scientific Research (FWO), Flanders, Belgium (G.0585.09), la Fondation pour la Recherche Médicale (FRM), Journées Neurologiques de Langue Française (JNLF). GVdB, through the University of Leuven, receives long-term structural research financing via the Methusalem program, funded by the Flemish government (METH/08/07) and holds a European Research Council Advanced Grant (AdvG-2012-321670) from the Ideas Programme of the EU FP7.

\section{CONFLICT OF INTEREST}

The authors declare that they have no conflict of interest. 


\section{FIGURE LEGENDS}

\section{Fig. 1 Glucose transport and substrate shuttling in the brain}

A : Glucose enters the brain interstitium via the $55 \mathrm{kDa}$ GLUT1 transporter in the luminal and abluminal plasma membranes of blood-brain barrier endothelial cells. Neurons take up glucose via GLUT3 transporters, convert it to pyruvate via glycolysis (yielding 2 ATP per molecule of glucose) and metabolize it further via the tricarboxylic acid (TCA) cycle and oxidative phosphorylation (yielding 17 ATP per molecule of pyruvate). Glucose is delivered to the astrocytes via the $45 \mathrm{kDa}$ GLUT1 transporter in the plasma membranes of astrocytic end-feet. Astrocytes also contain a small glycogen stock (not shown) that can be mobilized on brain activation and subsequently refilled with blood glucose.

B : During neural activity, neuronal depolarization induces an influx of sodium which in turn contributes to liberation of glutamate (Glu). Intracellular ATP is used by the Na/K ATPase in order to restore ionic homeostasis. The ATP concentration in the neurons ([ATP]i) decreases, thereby releasing the negative feedback of ATP on the glycolytic enzymes (hexokinase, phosphofructokinase, and pyruvate kinase) and stimulating glycolysis. Brain activation is associated with increased activity at glutamatergic synapses and the released glutamate is taken up by the astrocytes in cotransport with sodium (via specific glutamate transporters). The intracellular sodium load in astrocytes is removed via the $\mathrm{Na} / \mathrm{K}$ pump that consumes ATP and thereby stimulates astrocytic glycolysis. During intense neuronal activation or when glucose is lacking, lactate, the endproduct of glycolysis in astrocytes (by conversion from pyruvate via LDH5), leaves the cells via MCT1 mono-carboxylate transporters and is taken up by the neurons via MCT1 and MCT2 (astrocyte-neuron lactate shuttle hypothesis). In the neurons, lactate is converted to pyruvate via LDH1 and is further degraded oxidatively. Glutamate is recycled via the glutamate-glutamine (gln) cycle acting between astrocytes and neurons. 
TABLES

Table 1 Glucose and monocarboxylate transporters in the brain

\begin{tabular}{|c|c|c|c|c|}
\hline & $\begin{array}{l}\text { Location } \\
\text { in the brain }\end{array}$ & $\begin{array}{l}\text { Brain } \\
\text { cell type(s) }\end{array}$ & $\mathbf{K}_{\mathrm{m}}(*)$ & $\begin{array}{l}\text { Insulin } \\
\text { sensitivity }\end{array}$ \\
\hline GLUT1 & Widespread & $\begin{array}{l}\text { Astrocytes, choroid } \\
\text { plexus, ependymal cells } \\
\text { (Iso-45) } \\
\text { Endothelium (Iso-55) }\end{array}$ & 5-8 mM & No \\
\hline GLUT2 & Hypothalamus & $\begin{array}{l}\text { Glucosensing cells : } \\
\text { Astrocytes, neurons }\end{array}$ & $15-20 \mathrm{mM}$ & No \\
\hline GLUT3 & Widespread & $\begin{array}{l}\text { Neurons } \\
\text { (Neuropil) }\end{array}$ & $1-3 \mathrm{mM}$ & No \\
\hline GLUT4 & Widespread & $\begin{array}{l}\text { Neurons } \\
\text { (somatodendritic) }\end{array}$ & 4-5 mM & Yes \\
\hline GLUT5 & Widespread & Microglia & $(* *)$ & No \\
\hline GLUT8 & Widespread & $\begin{array}{l}\text { Neurons } \\
\text { (somatodendritic) }\end{array}$ & $2 \mathrm{mM}$ & Yes \\
\hline MCT1 & Widespread & $\begin{array}{l}\text { Neurons, astrocytes } \\
\text { Microglia } \\
\text { Choroïd plexus }\end{array}$ & 3-5 mM & No \\
\hline MCT2 & Widespread & Neurons & 0.5-0.7 mM & No \\
\hline МСТ3 & Widespread & $\begin{array}{l}\text { Neurons } \\
\text { Choroid plexus }\end{array}$ & $6 \mathrm{mM}$ & No \\
\hline MCT4 & Widespread & Astrocyte & 8-30 mM & No \\
\hline
\end{tabular}

GLUT: glucose transporter, MCT: monocarboxylate transporter.

(*): Only for GLUT1, GLUT3, MCT1, MCT2 and MCT4 reported $\mathrm{K}_{\mathrm{m}}$ values have been obtained for brain cells. $K_{m}$ values are given for glucose (GLUTs) or lactate (MCTs). A higher $K_{m}$ indicates a lower affinity.

(**): Glucose transport activity reported for rat GLUT5 but not for human GLUT5. 
Table 2 Randomized controlled studies in critically ill patients with acute brain injury comparing normoglycemia versus tolerating hyperglycemia

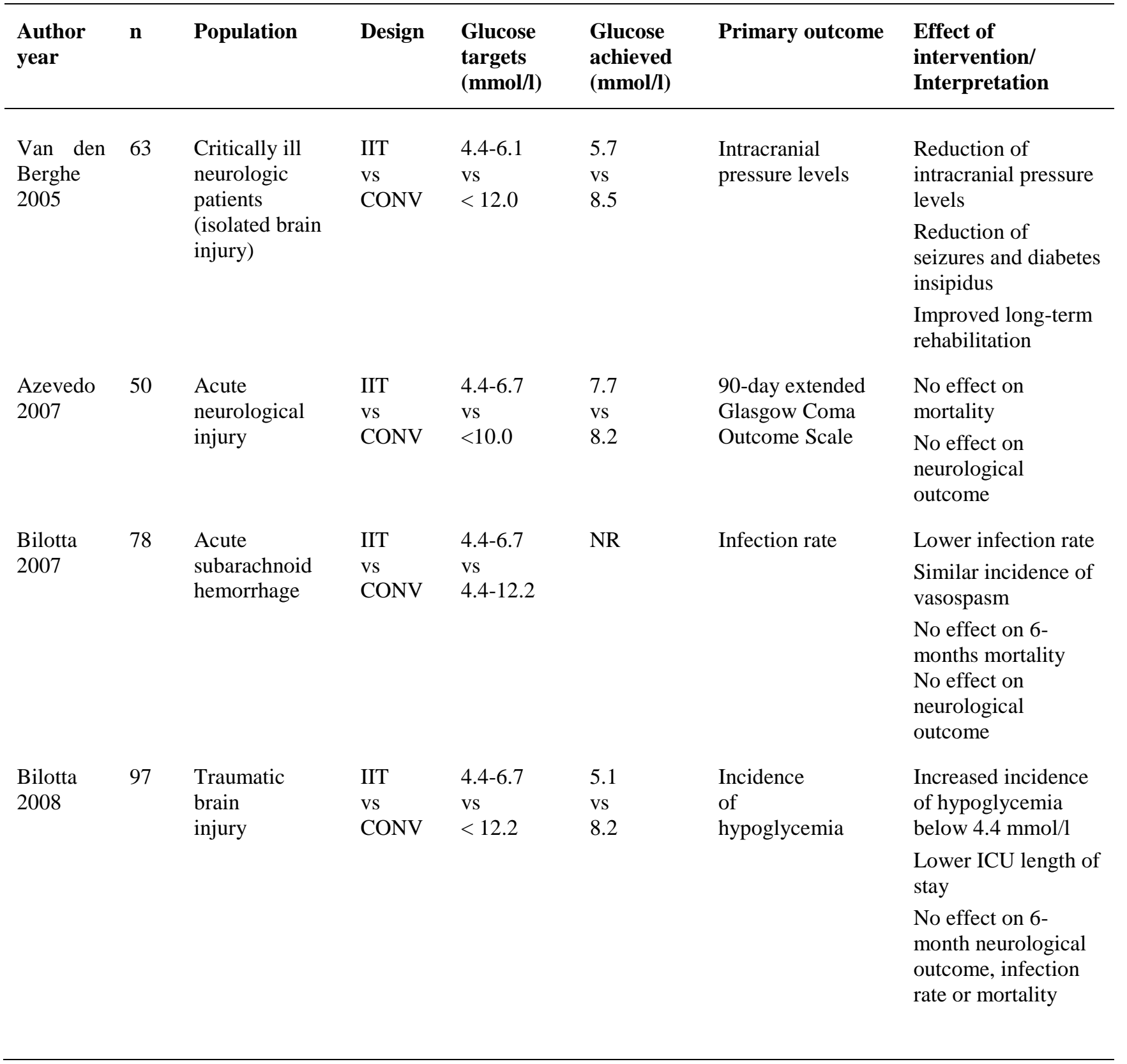


Table 2 Randomized controlled studies in critically ill patients with acute brain injury comparing normoglycemia versus tolerating hyperglycemia (continued)

\begin{tabular}{|c|c|c|c|c|c|c|c|}
\hline $\begin{array}{l}\text { Author } \\
\text { year }\end{array}$ & $\mathbf{n}$ & Population & Design & $\begin{array}{l}\text { Glucose } \\
\text { targets } \\
(\mathrm{mmol} / \mathrm{l})\end{array}$ & $\begin{array}{l}\text { Glucose } \\
\text { achieved } \\
(\mathrm{mmol} / \mathrm{l})\end{array}$ & Primary outcome & $\begin{array}{l}\text { Effect of } \\
\text { intervention/ } \\
\text { Interpretation }\end{array}$ \\
\hline $\begin{array}{l}\text { Yang } \\
2009\end{array}$ & 240 & $\begin{array}{l}\text { Traumatic brain } \\
\text { injury }\end{array}$ & $\begin{array}{l}\text { IIT } \\
\text { vs } \\
\text { CONV }\end{array}$ & $\begin{array}{l}4.4-6.1 \\
\text { Vs } \\
<11.1\end{array}$ & NR & $\begin{array}{l}\text { 6-month } \\
\text { mortality }\end{array}$ & $\begin{array}{l}\text { No effect on } \\
\text { mortality } \\
\text { Lower infection } \\
\text { rate ; shorter stay } \\
\text { Better neurological } \\
\text { outcomes }\end{array}$ \\
\hline $\begin{array}{l}\text { Bilotta } \\
2009\end{array}$ & 483 & $\begin{array}{l}\text { Post-operative } \\
\text { neurosurgery }\end{array}$ & $\begin{array}{l}\text { IIT } \\
\text { vs } \\
\text { CONV }\end{array}$ & $\begin{array}{l}4.4-6.1 \\
\text { Vs } \\
<11.9\end{array}$ & $\begin{array}{l}5.1 \\
\text { Vs } \\
8.0\end{array}$ & $\begin{array}{l}\text { Incidence } \\
\text { of hypoglycemia }\end{array}$ & $\begin{array}{l}\text { Increased incidence } \\
\text { of hypoglycemia } \\
\text { Lower ICU length of } \\
\text { stay and infection } \\
\text { rate } \\
\text { No effect on 6- } \\
\text { month neurological } \\
\text { outcome or mortality }\end{array}$ \\
\hline $\begin{array}{l}\text { Green } \\
2010\end{array}$ & 81 & $\begin{array}{l}\text { Critically ill } \\
\text { neurologic } \\
\text { patients }\end{array}$ & $\begin{array}{l}\text { IIT } \\
\text { vs } \\
\text { CONV }\end{array}$ & $\begin{array}{l}4.4-6.1 \\
\text { vs } \\
<8.3\end{array}$ & NR & $\begin{array}{l}\text { 3-month } \\
\text { mortality }\end{array}$ & $\begin{array}{l}\text { No effect on } \\
\text { mortality or length } \\
\text { of stay } \\
\text { No effect on } \\
\text { neurological } \\
\text { outcome }\end{array}$ \\
\hline $\begin{array}{l}\text { Coester } \\
2010\end{array}$ & 88 & $\begin{array}{l}\text { Severe } \\
\text { traumatic brain } \\
\text { injury }\end{array}$ & $\begin{array}{l}\text { IV IIT } \\
\text { vs } \\
\text { SC } \\
\text { CONV }\end{array}$ & $\begin{array}{l}4.4-6.1 \\
\text { Vs } \\
<10.0\end{array}$ & $\begin{array}{l}6.9 \\
\text { vs } \\
8.1\end{array}$ & $\begin{array}{l}\text { 6-months Glasgow } \\
\text { Outcome Scale }\end{array}$ & $\begin{array}{l}\text { No effect on } \\
\text { neurological } \\
\text { outcome, length of } \\
\text { stay or incidence of } \\
\text { sepsis }\end{array}$ \\
\hline
\end{tabular}

IIT: intensive insulin therapy, CONV: conventional glucose management, NSE: neuron-specific enolase, SC: subcutaneous; NR: not reported. [55, 57-63] 

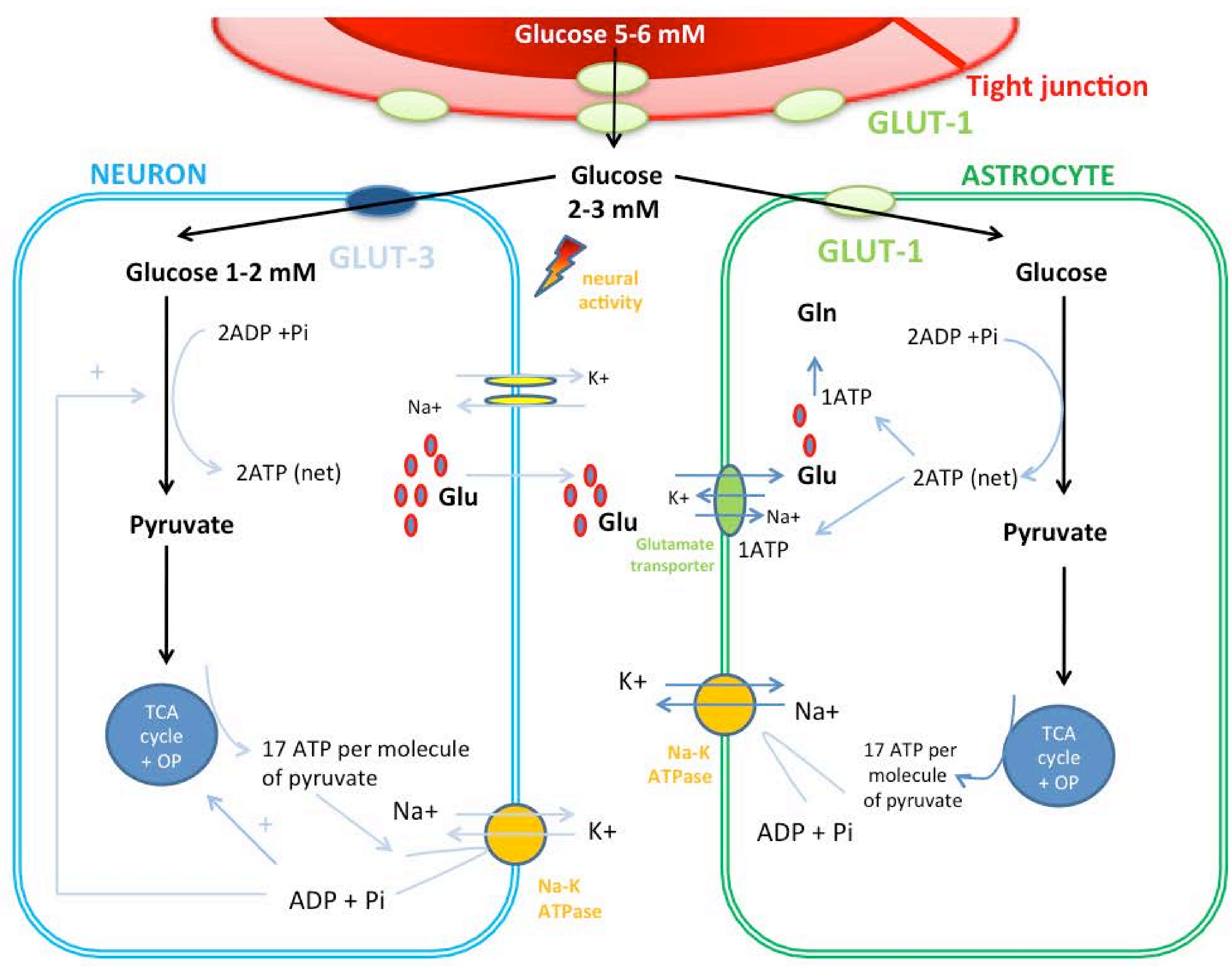

A
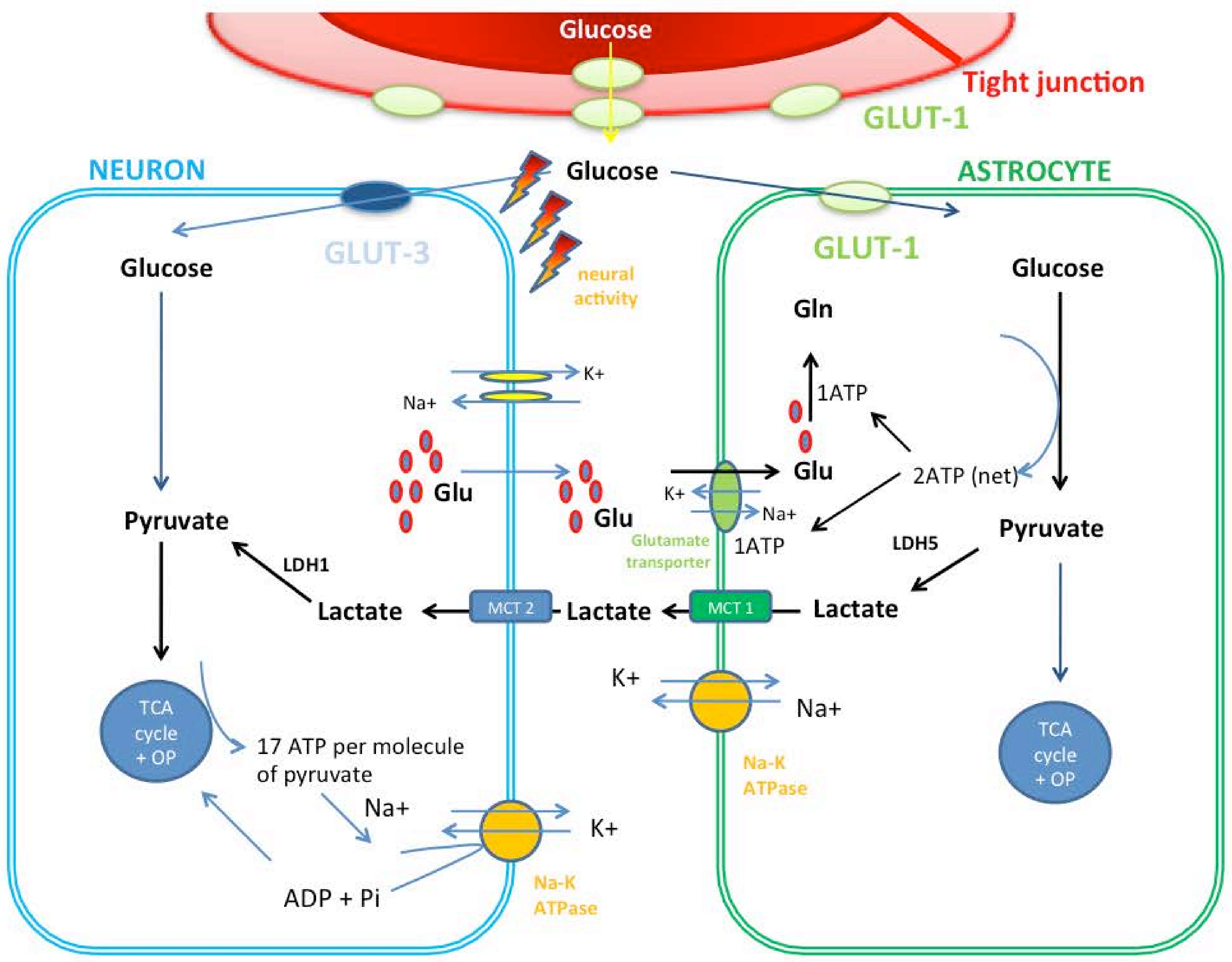